\title{
Patterns and Impacts of Short-Term Cross-Cultural Experience in Science and Mathematics Teaching: Benefits, Value, and Experience*
}

\author{
Kamonwan Kanyaprasith \\ Srinakharinwirot University, \\ Bangkok, Thailand
}

\author{
Fred N. Finley \\ University of Minnesota, \\ Twin Cities, USA
}

\author{
Nason Phonphok \\ Srinakharinwirot University, \\ Bangkok, Thailand
}

\begin{abstract}
This study evaluates a cross-cultural experience in science and mathematics teaching in Thailand—an internship program. In this study, qualitative data sources including semi-structured interviews, classroom observations, and pre-post questionnaire were collected from five groups of participants, which were: (a) administrators; (b) Thai cooperating teachers; (c) Thai students; (d) Thai graduate students; and (e) American graduate students. The results of data analysis from this study can be classified into six categories including: (a) role of participants; (b) value in teaching; (c) value in learning language; (d) value in learning different cultures; (e) value in professional and personal change; and (f) suggestions for the program. The research findings suggest that the future cross-cultural internship program can be developed as a school professional development program. The benefits and value that the participants have experienced are beyond the language learning.
\end{abstract}

Keywords: short-term, cross-cultural experience, science and mathematics teaching, internship program, exchange students

\section{Introduction}

One factor influencing how teachers teach and how students learn science is culture (Aikenhead \& Jegede, 1999). Science educators and curriculum developers are now paying more attention to cultural environment that may possibly affect students' view of science (Biescheuvel, 1992; Urevbu, 1984; Scribner \& Cole, 1973; Champagne, Gunstone, \& Klopper, 1983; Okere, Keraro, \& Andiit, 2013). In developing countries, science is usually perceived as a foreign culture derived from Western countries and it is difficult to connect with students' individual culture (Aikenhead, 1997; Jegede, 1995; Maddock, 1981; Aikenhead \& Jegede, 1999). This can lead to conflicts in their view of the world of science.

To help students overcome this major difficulty, teachers need to take the matter of different languages, cultures, and ethnic backgrounds into account, especially in the classrooms nowadays that consist of many diverse learners. Based on the United States (U.S.) immigration statistics, the foreign-born populations are tripled in the past four decades and represent nearly 12\% of the total population in the year 2005 (Capps, Fix,

\footnotetext{
*Acknowledgement: This work was funded by the Science Education Center, Srinakharinwirot University, Bangkok, Thailand. Kamonwan Kanyaprasith, Ed.D., instructor, Science Education Center, Srinakharinwirot University.

Fred N. Finley, Ph.D., associate professor, College of Education and Human Development, University of Minnesota. Nason Phonphok, Ph.D., associate professor, Science Education Center, Srinakharinwirot University.
} 
Murray, Ost, Passel, \& Herwantoro, 2005). This increasing number of immigrant population in the U.S. calls for the improvement of the education for children of immigrants who have limited English proficiency (Capps et al., 2005; Passel, 2006). Therefore, to prepare teachers in terms of handling the classroom with diverse learning backgrounds, school and teacher educational programs need to thoroughly design courses or extracurricular activities for in-service and pre-service teachers to be ready for such situations.

Many teacher education programs have turned their attention to focus on international and intercultural teaching programs. As in the U.S., a number of universities have developed special and unique programs for experiencing international perspectives (Kissock, 1996; Cushner \& Mahon, 2002; Stachowski, Richardson, \& Henderson, 2003; Quezada, 2004; Cushner, 2007). Such universities include the Consortium for Overseas Student Teaching (COST) (Cushner \& Mahon, 2002), the Cultural Immersion Project at Indiana University at Bloomington (Stachowski et al., 2003), and Global Student Teaching (Kissock, 1996). As a result, schools of education attempt to prepare pre-service teachers by designing internationally-focused courses, supporting foreign language education, and offering extracurricular activities especially overseas experiences program (Cushner, 2007). Recent researches show that experience in teaching overseas can impact pre-service teachers regarding self-knowledge, personal confidence, professional competence, and awareness of global and domestic diversity (Cushner \& Mahon, 2002; Stachowski et al., 2003; Cushner, 2004). Since the number of the cross-cultural experience programs has recently increased, questions, such as what and how pre-service teachers learn or change in terms of cognitive, affective, and behavioral domains after experiencing the program, what the benefits are, and how pre-service teachers who participate in the program are different from those who are not, are raised to the stakeholders (Cushner, 2007). In this paper, the evaluation of a cross-cultural experience in an internship program will be discussed. The program is organized by three main stakeholders, including a university in the center of Thailand, a university in the mid-west of the U.S., and five secondary schools in Thailand.

\section{Background of the Cross-Cultural Experience in Science and Mathematics Teaching Program in Thailand}

During the intersession between spring and summer, a university in the center of Thailand, a university in the mid-west of the U.S., and five secondary schools in Thailand have provided an opportunity to work collaboratively with Thai teachers and students through an internship program, which encourages the participants to share science and mathematics teaching experiences across cultures with people from other cultures.

In this program, the participants will study Thai culture and educational system, gain a new perspective on educational opportunities and difficulties in the U.S. educational system, and have better understanding on their own teaching. In addition, as $10 \%$ of the population in Minnesota are Hmong immigrants (the Asian ethnic group from the region near Thailand, Myanmar, Laos, and China), another benefit of the program is that American graduate students and pre-service teachers will learn some Thai culture, which is a part of the culture of many Hmong immigrants, from their time with Thai students and can adapt it with the Hmong students in their future classroom. The experience from the internship will provide the foundation for many future teachers to gain the working experience in other cultures. The objectives of the Cross-Cultural Experience in Science and Mathematics Teaching program are as following.

The objectives of the program were to enable the participants to: 
1. Understand how to teach students who are from other cultures and who have limited English proficiency;

2. Understand the ways in which culture influences educational systems through the experience of participating in and teaching in an unfamiliar culture;

3. Learn new ways of teaching science and mathematics from another culture;

4. Compare the educational system of Thailand to that of the U.S.;

5. Gain a new perspective on educational opportunities, strengths, and problems of the U.S. educational system;

6. Learn Thai culture which is part of the culture of many Hmong immigrants who have joined in U.S..

\section{Methodology}

The study was conducted in a naturalistic paradigm using qualitative techniques for data collection and data analysis for studying participants' perspective. We used constant comparative method (Glaser \& Strauss, 1967) to analyze and gain an in-depth understanding of this program and its meaning for those involved in the program.

\section{Objectives}

The purpose of this research is to study participants' perspective during and after participating in the program and to seek for the patterns and impact regarding experience in the program.

\section{Data Collection}

In this study, the researchers and research assistants acted as participant observers and interviewers. As the participant observers, we attended the participant team during planning and teaching in classroom. We gathered data from: (a) field notes from ongoing observations; (b) documentary sources; (c) semi-structured interviews and audio recordings; and (d) pre-post questionnaire (see Appendix). The interview protocol and questionnaire were created by the researchers. Triangulation was assured by obtaining data from these various sources. All data were transcribed through manual coding (Glaser \& Strauss, 1967).

\section{Data Analysis}

The constant comparative method (Glaser \& Strauss, 1967) was applied for analyzing data in order to develop a grounded theory. This process involves: (a) preparing or identifying a phenomenon; (b) segmenting; (c) coding; (d) comparing and categorizing; and (e) themetizing and seeking for patterns and relationships. The findings were validated for internal validity by using member checking, respondent validation, and peer examination (Creswell, 2007; Merriam, 1998; Yin, 2003). The analysis led to six categories of findings.

\section{Findings}

The results of data analysis from this study can be classified into six categories including: (a) role of participants; (b) value in teaching; (c) value in learning language; (d) value in learning different cultures; (e) value in professional and personal change; and (f) suggestions for the program.

\section{Role of Participants}

Based on 26 informants including American graduate students, Thai graduate students, Thai teachers, and school principals, the following are the roles perceived by the participants, which were summarized from the questionnaire: 
1. A school principal was the planner/manager of the program;

2. Two Thai teachers were a coordinator and a facilitator who are responsible for contacting between American graduate students and people at school;

3. The other two Thai teachers were colleagues of American graduate students who are responsible for planning and teaching;

4. One Thai teacher was a "cooperative teacher" or "mentoring teacher";

5. Six Thai graduate students were translators and colleagues;

6. Four Thai graduate students expressed that they were unsure about their roles in the program;

7. Ten American graduate students were teachers responsible for teaching science and math and learning to work in the Thai culture.

We have analyzed the response above and found that less than half of them can correctly identify their own roles in the program. Moreover, most of the participants are unsure about the roles of the others working with them during the program.

\section{Value in Teaching}

Thai teachers expressed that the internship program creates value toward teaching because this is a good opportunity for them to learn new teaching technique from American graduate students. For example, American graduate students encouraged Thai students to do more hands-on activities and use games in the classroom. Thai teachers have observed American graduate students and express that the teaching strategies American graduate student used are different. They focus on understanding science phenomena rather than solving the tasks in the textbook.

The following is an example of an input data sources from an interview. The names have been changed to protect the privacy of the participants.

The program has so much effect on me in terms of teaching. I have learned a lot of teaching theory but have never actually tried out in practice. When seeing American graduate students create lesson plans, I realize I could learn and use their techniques in my class. I am certain that my students will like it. Students should work as a group at least once a week. (TEA)

Meanwhile, American graduate students expressed that this is a good opportunity for them to observe instructional techniques and collaborate with Thai experienced science teachers. They have an opportunity to develop and implement a new lab for Thai students and this is useful for them in the future classroom.

Developing and implementing the two respiration labs took a lot of time and energy. It was the first time I had designed a lesson like this on my own and was able to try them out in the classroom. Professionally, it was very exciting and successful. Personally, it felt like a great accomplishment, especially because I was worried that I would not be able to come up with the activities that would challenge these exceptional students. Now I have two great lessons to use with my students here. (SR)

It was very informative to learn of challenges, struggles, and successes of different instructional techniques they use in their classroom. I have not previously had many opportunities to collaborate with science teachers to hear how they teach science and discuss different methods. I am incredibly grateful to have had these interactions with the Thai teacher. (RC)

\section{Value in Learning Language}

Every Thai participant feels that this internship program provides them a chance to practice English with native speakers which is very useful for both Thai students and teachers.

The following are examples from an interview concerning the category of "value in learning language": 
Our school is in a rural area. A chance to have English native speakers in school is rare. It is good that the university chooses us and sends American and Thai graduate students here. This program helps me and students practice English and parents also love to see the school have this kind of activity. (TK1)

The best experience I have learnt during this program is the communication in English, especially for teaching math, including how to use symbol, as well as reading and listening skills. It allows me (teacher) to gain more confidence in speaking and communicating with students, and students have an opportunity to practice and have familiarity and courage to speak. In addition, both teachers and students have a positive attitude toward learning math in English. This should contribute to success in future English-integrated school (EIS) classroom. (SS)

\section{Value in Learning Different Cultures}

Learning to work in different cultures is one of the main goals of this program. Based on the semi-structured interviews, the data show how American graduate students perceive and learn about Thai people and culture.

The following are the examples of the feedback participants' responses:

Respect for adults is deeply ingrained in the Thai culture. In the school system, this becomes intensely clear as you enter a Thai classroom. The students show a great deal of respect toward their teachers. Class starts by the students welcoming their teacher with hello and bow in unison, and ends similarly with the entire class thanking the teacher for the day's lesson and all together bows in unison. (AST4)

The way Thai people have of handling things or planning things is so different from that in America. On our visit in (places in Thailand), we usually had no idea what would happen next. In the American school system, the school events are arranged and planned before the beginning of the semester. However, in the school I was teaching at in Thailand, I experienced changes of schedule for special events for reasons I never learned. The planning was changing constantly. It really drove me crazy. (GS2)

\section{Value in Professional and Personal Change}

Based on participants' reflection and interview, we found that American graduate students learn and see themselves differently, in comparison with the attitudes perceived before participating in the program. They seemed to understand the situation that minority students may encounter when they are in the place that they become the minority.

The following are examples from interview and reflection data sources concerning the category of "value in professional and personal change":

I feel I am a different person coming back from Thailand. For one thing, I have such a tremendous amount of respect for the English language learner (ELL) students in American school. I have always empathized with these students as I thought I understood how difficult it must be to follow along in a lesson with an unsure grasp of a new language. (AST6)

However, after being put in the position of being an ELL student in Thailand, my views on ELL students in American has been revised. I understand now that students from a foreign culture do not just have difficulty with the lesson; they have difficulty with all aspects of communication. (AST6)

\section{Suggestion for the Program}

Although the participants tend to report the positive attitude toward the program, there are a number of comments and suggestions raised for the future program. For example, a principal of one school reveals his concern as following:

What I concern and would like to suggest is the foreigner's culture, which may not be appropriate for our school's context. For example, foreign teachers sometimes wear shorts and have nose piercing. I am worried that the students may emulate this behavior. This is an issue that our school is always very strict about. Although, it is not a really serious issue based on my opinion, our students should not follow it as an example. I think foreign teachers understand it and are trying 
to adapt themselves. (Pri.Sch.2)

The following are comments that reflect to the program from American graduate students:

Lecturing is the main mode of science instruction. The American way of inquiry-based teaching is not seen in any classroom. Students are used to teacher-centered teaching. They seldom ask questions and are afraid and embarrassed to give wrong answers. However, science teachers are eager to search for change and improvement. ... By using the knowledge, I was able to plan my lessons with pictures from my laptop, demonstrations, posters, and some hands-on experiments. With time and practice, students came to enjoy the activities. I am confident that Thai students are able to learn science through student-centered teaching. It is a matter of practice and opportunities. Maybe, if it is possible, the university can hold workshops in science teaching for Thai teachers, and invite Thai teachers to observe science teaching in American high schools. (AST8)

\section{Discussion and Conclusion}

In this 21st century, the world becomes interconnected and it cannot be denied from an educational point of view that teachers and students nowadays need sufficient knowledge and skills to work with others with different cultural backgrounds. However, only few are well aware and prepared for this situation. This is also consistent with Sleeter (2008) that more research is required in exploring the impact of an immersion experience on teachers in learning cross-cultural and global awareness (Sleeter, 2001; Yali, 2007; Carter, 2007). In this study, we explore participants' perspective during and after participating in the Cross-Cultural Experience in Science and Mathematics Teaching program and to seek for the patterns and relationships.

Based on the findings, the impacts of the program were classified as patterns between: (a) learners' science learning; (b) teachers’ professional development; (c) principals' English teaching policy; and (d) graduate students' learning different cultures. The patterns and impacts are described as following:

1. Attitude of learners toward learning science: Learners gained benefits from science learning since they expressed that they have more opportunity in using science equipment, conducting experiments, and experiencing new and various learning activities. In addition, not only can the students recall science content learnt during the program, but they are also able to indicate how to apply it in daily life;

2. Attitude of teachers toward professional development: Teachers gained benefits in terms of professional development from the program. They felt that the program provided them with an opportunity to develop professional teaching without having to leave their schools. After working with Thai and American graduate students, teachers have been motivated to learn a variety of knowledge and skills from others, which enable them to improve themselves in teaching science;

3. Attitude of principals toward English teaching policy: It can be concluded that principals tend to focus on the policy of teaching science in English. Nowadays, parents pay more attention to English program schools, such as EIS and Mini English Program (MEP). This internship program provides school principals with the vision in supporting Thai teachers to develop their capacity in using English in their schools. Furthermore, arranging the program at least once a year also helps attract attention from parents and build a good reputation of the schools;

4. Attitude of graduate students toward learning different cultures: American graduate students, as foreigners in Thailand, have understanding on how foreign or non-native students in the U.S. would experience. As a result of difference in culture and attitude, the American students understand the difficulties, which students may have, in both the lesson and the communication between students and teachers (McAllister \& Irvine, 2002). This experience from the program will help them carefully design their future lesson plan for a multicultural classroom. 
Positive attitude of Thai students toward the program was shown in the interview. American graduate students, Thai teachers, and Thai graduate students conducted science classroom together as a team, which provided an opportunity for the students to experience a variety of science learning models and teaching techniques. Similar to the Thai students, the American students also have positive attitude toward the program because the personalities of both American and Thai graduate students are friendly and open-minded. Moreover, Thai teachers and school principals help American teachers experience Thai culture not only in school, but also after school and during weekend activities.

According to the findings, the participants understand their roles in the program, but they cannot clearly express the understanding of their responsibilities in the program. This issue could be due to the tight process which required that participants who volunteered to teach in Thailand were able to confirm about only two months prior to the start of the program. As a result, the organizer team could not contact the Thai participating schools as early as it should have been. In order to address this issue, there should be more time for internal cooperations in advance (e.g., one semester earlier) in order to plan and prepare necessary materials for the lessons relating to Thai curriculum. It is essential that the program organizer should consider recruiting volunteers in early fall semester, so that the participants have sufficient time to prepare themselves and understand their responsibilities during the program.

\section{Recommendations}

The research findings suggest that the future cross-cultural internship program can be developed as a school professional development program, since according to the interview, Thai teachers and students acknowledge the benefit and value of the program for developing science learning and teaching beyond those of language learning. Teachers tend to have an inner motivation in teaching science by using student center, active learning, inquiry-based learning, activity-based learning, etc.. In the future, professional developers should further improve the model of cross-cultural internship and cross-cultural school-based professional development programs, to ensure that both pre-service and in-service teachers and learners are well prepared for multicultural classroom. This study shows that it is important and necessary for mathematics and science teachers to have an opportunity to teach, work, and learn with foreign teachers to gain a different perspective from them.

\section{References}

Aikenhead, G. S. (1996). Science education: Border crossing into the subculture of science. Studies in Science Education, 27, $1-52$.

Aikenhead, G. S. (1997).Toward a first nations cross-cultural science and technology curriculum. Science Education, 81, $217-238$.

Aikenhead, G. S. (1998). Many students cross cultural borders to learn science: Implications for teaching. Australian Science Teachers' Journal, 44(4), 9-12.

Aikenhead, G. S. (2001). Integrating western and aboriginal science: Cross-cultural science teaching. Research in Science Education, 31(3), 337-355.

Aikenhead, G. S., \& Jegede, O. J. (1999). Cross-cultural science education: A cognitive explanation of a cultural phenomenon. Journal of Research in Science Teaching, 36, 269-287.

Baxter, P., \& Jack, S. (2008). Qualitative case study methodology: Study design and implementation for novice researchers. The Qualitative Report, 13(4), 544-559. Retrieved from http://www.nova.edu/ssss/QR/QR134/baxter.pdf

Biescheuvel, S. (1992). The ability of African children to assimilate the teaching of science. In P. G. S. Gibert, \& M. N. Lovegrove (Eds.), Science education in Africa. London: Cheinemamn Educational Books Ltd.. 
Brenda, R. B., \& George, E. G. (2004). Crossing borders into science teaching: Early life experiences racial and ethnic identities, and beliefs about diversity. Journal of Research in Science Education, 41, 119-141.

Capps, R., Fix, M., Murray, J., Ost, J., Passel, J. S., \& Herwantoro, S. (2005). The new demography of America's schools. Washington, D.C.: The Urban Institute.

Carter, L. (2007). Sociocultural influences on science education: Innovation for contemporary times. Science Education, 92(1), 165-181.

Champagne, A. B., Gunstone, R. F., \& Klopper, L. E. (1983). Naïve knowledge and science learning. Research in Science and Technological Education, 1(2), 173-183.

Cook, R. (2009). The effects of a short-term teacher abroad program on teachers' perceptions of themselves and their responsibilities as global educators (Ph.D. dissertation, Utah State University). Retrieved November 15, 2013, from http://www.digitalcommons.usu.edu/etd/375/

Creswell, J. W. (2007). Qualitative inquiry and research design: Choosing among five approaches (2nd ed.). Thousand Oaks, C.A.: Sage.

Cushner, K. (2004). Beyond tourism: A practical guide to meaningful educational travel. Lanham, M.D.: Rowman and Littlefield/Scarecrow Education.

Cushner, K. (2007). The role of experience in the making of internationally-minded teachers. Teacher Education Quarterly, 34(1), 27-39.

Cushner, K., \& Mahon, J. (2002). Overseas student teaching: Affecting personal, professional and global competencies in an age of globalization. Journal of Studies in International Education, 6(1), 44-59.

Glaser, B. G., \& Strauss, A. L. (1967). The discovery of grounded theory: Strategies for qualitative research. New York, N.Y.: Aldine De Gruyter.

Hovater, S. (2007). Developing cultural awareness: A grounded theory study of pre-service teachers' field experiences in Taiwan. (Doctoral dissertation, University of Nebraska). Dissertation Abstracts International, 68, 241. Retrieved from http://digitalcommons.unl.edu/cehsdiss/14

Jegede, O. (1995). Collateral learning and the eco-cultural paradigm in science and mathematics education in Africa. Studies in Science Education, 25, 97-137.

Kissock, C. (1996). Student teaching overseas. In M. Merryfield, E. Jarchow, \& S. Pickert (Eds.), Preparing teachers to teach global perspectives: A handbook for teacher educators. Thousand Oaks, C.A.: Corwin Press.

Maddock, M. N. (1981). Science education: An anthropological viewpoint. Studies in Science Education, 8, 1-26.

McAllister, G., \& Irvine, J. J. (2002). Cross cultural competency and multicultural teacher education. Review of Education Research, 70(1), 3-24.

Merriam, S. B. (1998). Qualitative research and case study applications in education. San Francisco, C.A.: Jossey-Bass Publishers.

Okere, M. I. O., Keraro, F. N., \& Andiit, Z. O. (2013). Pupils' cultural interpretations of causes of rainbow in Kenya. Journal of Education and Social Research, 3(1), 169-177.

Passel, J. S. (2006). The size and the characteristics of the unauthorized migrant population in the U.S.. Washington, D.C.: Pew Hispanic Center.

Quezada, R. L. (2004). Beyond educational tourism: Lessons learned while student teaching abroad. International Education Journal, 5(4), 458-465.

Scribner, S., \& Cole, M. (1973). Cognitive consequences of formal and informal education. Science, 82, 556-559.

Sleeter, C. E. (2001). Preparing teachers for culturally diverse schools: Research and the overwhelming presence of whiteness. Journal of Teacher Education, 52(2), 94-106.

Sleeter, C. E. (2008). Preparing white teachers for diverse students. In M. Cochran-Smith, S. Feiman-Nemser, \& J. McIntyre (Eds.), Handbook of research in teacher education: Enduring issues in changing contexts (3rd ed., pp. 559-582). New York, N.Y.: Routledge.

Stachowski, L., Richardson, W. J., \& Henderson, M. (2003). Student teachers report on the influence of cultural values on classroom practice and community involvement: perspectives from the Navajo reservation and abroad. The Teacher Educator, 39(1), 52-63.

Urevbu, A. O. (1984). School science curriculum and innovation: An African perspective. European Journal of Science Education, 6, 217-225. 
Ward, A. (1998). The role of mentorship in a Saskatchenom cross-cultural teacher education project Mcgill. Journal of Education, 33(3).

Yali, Z. (2007). Impact of immersion experience in an immigrant community on pre-service teachers' cross-cultural and global awareness. Journal of Education and Human Development, 1(2), 1-10.

Yin, R. K. (2003). Case study research: Design and methods (3rd ed.). Thousand Oaks, C.A.: Sage.

Zoogah, D. B., \& Abbey, A. (2010). Cross-cultural experience, strategic motivation and employer hiring preference: An exploratory study in an emerging economy. International Journal of Cross Cultural Management, 10(3), 321-343. 


\section{Appendix: Pre-Post Questionaire}

Name:

Age:

\section{Prelude Questionnaire}

A. Write a list of at least five pre-experience questions you have? More than five questions are welcome.

B. Write responses to the following questions:

1. What do you expect to learn that will be professionally valuable?

2. What do you expect to learn that will be personally valuable?

3. What do you expect will be the best part of the experience?

4. What challenges do you expect?

5 . How do you think the experience will change you professionally?

6. How do you think the experience will change you personally?

\section{Post Questionnaire Protocol}

1. What did you learn that is professionally valuable?

2. What did you learn that is personally valuable?

3. What did you learn that is the best part of the experience?

4. What challenges did you learn?

5 . How do you think the experience will change you professionally?

6. How do you think the experience will change you personally? 